\title{
A adequação à exploração do mercado de trabalho via segmentação da Licenciatura e Bacharelado em Educação Física
}

\section{The adjustment to the labor market's exploitation via the segmentation of Physical Education's graduation in teacher and bachelor degrees.}

\section{Adecuación a la explotación del mercado laboral mediante la segmentación de la Licenciatura y el Bachillerato en Educación Física.}

\author{
iD (9) Carla Chagas Ramalho \\ Universidade Estadual de Montes Claros - Montes Claros - Minas Gerais - Brasil \\ e-mail: carlaramalho.ccr@gmail.com \\ (iD) Fernanda de Souza Cardoso \\ Universidade Estadual de Montes Claros - Montes Claros - Minas Gerais - Brasil \\ e-mail: fernanda.cardoso@unimontes.br
}

Resumo: Neste ensaio focamos na influência do mercado profissional na formação em Educação Física, e temos como objetivo central analisar como as Diretrizes Curriculares Nacionais de Educação Física (Resolução no 03/1987 e Resolução no 07/2004), embasadas nos princípios capitalistas, fomentaram a precarização do trabalho no campo da Educação Física através da segmentação do curso em Licenciatura e Bacharelado. Como metodologia, utilizamos a pesquisa bibliográfica das diretrizes referidas. Concluímos que a forte influência do setor econômico capitalista acabou por ampliar uma precarização na área da Educação Física, tendo uma especialização precoce de conhecimentos científicos voltados para a área de atuação profissional.

Palavras-chave: Educação Física; Licenciatura; Bacharelado; Mercado de trabalho. 
Abstract: In this essay we focus on the influence of the professional market in Physical Education training, with the central objective of analyzing how the National Curriculum Guidelines for Physical Education (Resolution No. 03/1987 and Resolution No. 07/2004), based on capitalist principles, fostered the precariousness of the work in the field of Physical Education through the segmentation of the course in Licenciatura and Bacharelado. As methodology we use the bibliographic research of the referred guidelines. We conclude that the strong influence of the capitalist economic sector ended up increasing a precariousness in the area of Physical Education, having an early specialization of scientific knowledge aimed at the area of professional performance.

Keywords: Physical Education; Graduation; Bachelor degree; Labor market.

Resumen: En este ensayo nos enfocamos en la influencia del mercado profesional en la formación en Educación Física, con el objetivo central de analizar cómo los Lineamientos Curriculares Nacionales de Educación Física (Resolución No. 03/1987 y Resolución No. 07/2004), basados en principios capitalistas, fomentaron la precariedad de la trabajar en el campo de la Educación Física a través de la segmentación del curso en Licenciatura y Bacharelado. Como metodología utilizamos la búsqueda bibliográfica de las referidas guías. Concluimos que la fuerte influencia del sector económico capitalista terminó por incrementar una precariedad en el área de la Educación Física, teniendo una temprana especialización del conocimiento científico orientado al área del desempeño profesional.

Palabrasllave: Educación Física; Graduación; Grado de bachiller; Mercado de trabajo. 
A adequação à exploração do mercado de trabalho via segmentação da Licenciatura... Carla Chagas Ramalho • Fernanda de Souza Cardoso

\section{Introdução}

$\mathrm{Na}$ atualidade vivemos em uma realidade econômica ramificada do capitalismo definido por Marx e Engels (1999), pois depois de crises e remodelagens econômicas, o capitalismo não possui mais um nome simples, e sim um nome composto, como: capitalismo neoliberal e capitalismo financeiro (MOREIRA, 2019; 2020). No entanto, sua essência não se altera e a mais valia vive em voga para o sustento primário desse sistema, mesmo que com adaptações primordiais.

Sendo o capitalismo mais do que um sistema econômico, pois ele acaba por moldar as relações sociais, culturais e políticas da sociedade, seus Aparelhos Ideológicos (ALTHUSSER, 1980) são cruciais para a manutenção da sua ordem e acabam por adaptar as novas demandas. E, tendo a escola como o Aparelho Ideológico do Estado (AIE) dominante (ALTHUSSER, 1980), consideramos primordial analisar os currículos que embasam a realidade escolar para dimensionarmos a ação efetiva desse Aparelho.

Neste ensaio iremos focar em como a realidade do sistema capitalista acabou por interferir diretamente na graduação de Educação Física, desmembrando-a em dois cursos (Licenciatura e Bacharelado). Assim, nosso objetivo neste estudo é analisar como as Diretrizes Curriculares Nacionais de Educação Física (Resolução no 03/1987 e Resolução no 07/2004), embasadas nos princípios capitalistas, fomentaram a precarização do trabalho no campo da Educação Física através da segmentação do curso em Licenciatura e Bacharelado.

Para isso, utilizaremos como metodologia a pesquisa bibliográfica (LAKATOS; MARCONI, 2002), utilizando como fonte primária os documentos intitulados como Resolução no 03/1987 e Resolução no 07/2004, as quais instituem as Diretrizes Curriculares para a graduação em Educação Física. Nesses documentos há a discriminação entre os campos de atuação no mercado de trabalho para a pessoa formada em Educação Física, como veremos a seguir, e 
A adequação à exploração do mercado de trabalho via segmentação da Licenciatura... Carla Chagas Ramalho • Fernanda de Souza Cardoso

é por meio dessa restrição de conhecimento científico específico atribuído a cada habilitação profissional que nós iremos nos debruçar, buscando investigar de que maneira o mercado de trabaIho (e a atuação direta dos propósitos capitalistas) moldou o caminho para uma precarização profissional.

\section{Diretrizes Curriculares}

Quando falamos sobre currículo, habitualmente nos remetemos ao ambiente escolar e ao ensino básico. Porém, os currículos e diretrizes curriculares das universidades, necessários para a formação científica de futuros(as) profissionais, também geram uma demanda de conhecimento e não devem fugir da atenção necessária para sua construção (YOUNG, 2014). Nesse sentido, há uma disputa de poderes incessante para demarcar as funcionalidades que cada diretriz deve vir a ter, pois ao permear pelo campo acadêmico, centro formador de profissionais de diferentes áreas da sociedade, o apelo do Estado se revigora, e é nessa ação que agem as engrenagens do Aparelho Ideológico (ALTHUSSER, 1980).

Porém, essa engrenagem não funciona de maneira fluida e sem oposição; para cada demanda trazida pelo Estado, habitualmente, há uma contraposição feita pela esfera crítica nesse viés educacional, principalmente pela Pedagogia Histórico Crítica (SAVIANI, 2011). Dessa forma, os embates sociais transpõem as organizações de diretrizes e parâmetros de currículos para a definição de o que é essencial para o(a) estudante (seja da Educação Básica ou do Educação Superior) aprender para sua vivência não só no ambiente educacional, mas que influenciará na sua visão de mundo, como também na sua maneira de intervir nele.

Nos anos de 1990 houve uma modificação significativa no campo político brasileiro; podemos ver como exemplo o presidente eleito em 1995, Fernando Henrique Cardoso, enaltecendo o ideário das políticas neoliberais com privatizações de setores públicos e redução do papel do Estado (NASCIMENTO; BARROS, 
A adequação à exploração do mercado de trabalho via segmentação da Licenciatura... Carla Chagas Ramalho • Fernanda de Souza Cardoso

2018), o que abriu espaço para implementação de ideais de instituições externas no âmbito educacional. Houve documentos de entidades, como o Banco Mundial (BM), a Comissão Econômica para a América Latina e Caribe (CEPAL), a Organização das Nações Unidas para a Educação, Ciência e Cultura (UNESCO), entre outros, empenhados em definir parâmetros e funcionalidades para a educação, estimando uma reforma educacional que abrangeria todos os segmentos de ensino (SILVA; ABREU, 2008).

É clara nas determinações da CEPAL e do Banco Mundial a orientação de que a reforma educacional e curricular deveria ocorrer, precipuamente, com o fim de adaptar a formação escolar às supostas demandas do setor produtivo. Isso contribuiu para um movimento no qual a extensão das mudanças econômicas extrapolasse o campo da produção e se configurasse em reestruturação geral da sociedade (SILVA; ABREU, 2008, p. 526, grifo nosso).

Nesse contexto, a prática do saber-fazer ganhou espaço no campo educacional, propiciando uma reformulação nos currículos educacionais voltada para as competências, sendo que "A noção de competência designará aqui a capacidade de mobilizar diversos recursos cognitivos para enfrentar um tipo de situações" (PERRENOUD, 2000, p. 15). E, ao começar a se encaixar no conceito de competências, o setor educacional abriu-se para o projeto econômico capitalista neoliberal de forma objetiva, pois, para a aplicabilidade do ensino das competências, precisava ser voltado para o seu papel prático em formar alunos(as) e, por consequência, trabalhadores(as) que se encaixassem no novo cenário econômico exigido. Logo, o ensino nas instituições escolares foi voltado para atribuir sentido prático e efetivo aos seus saberes, resultando que "[...] a formação responsabilizar-se-ia muito mais por ordenar as atitudes e práticas profissionais em coerência com a organização e o funcionamento dos processos de produção" (RAMOS, 2006, p. 222). 
A adequação à exploração do mercado de trabalho via segmentação da Licenciatura... Carla Chagas Ramalho • Fernanda de Souza Cardoso

Assim, para novos objetivos educacionais, surgiu o Plano Decenal de Educação para todos 1993-2003 (1993), a nova Lei de Diretrizes e Bases (1996) e os Parâmetros Curriculares Nacionais (1998; 1999), sendo todos esses documentos voltados para a Educação Básica. E, se era necessário modificar a função da Educação Básica, também era urgente alterar a formação dos(as) professores(as), exigindo a modificação de todo o cenário do Ensino Superior (não somente das licenciaturas), como podemos ver a seguir no documento formatado em 2000 pelo Fórum de PróReitores de Graduação das Universidades Brasileiras (FORGRAD):

\begin{abstract}
A graduação não deve restringir-se à perspectiva de uma profissionalização estrita, especializada. Há que propiciar a "aquisição de competências de longo prazo", o domínio de métodos analíticos, de múltiplos códigos e linguagens, enfim, uma qualificação intelectual de natureza suficientemente ampla e abstrata para constituir, por sua vez, base sólida para a aquisição contínua e eficiente de conhecimentos específicos (FORGRAD, 2000, p. 10, grifo nosso).
\end{abstract}

Fica claro como as determinações ou os cânones das instituições econômicas nortearam o cenário educacional nesse período, fomentando uma educação que propiciava uma modificação capitalista neoliberal, possibilitando mão de obra que fosse eficiente e competente no seu saber-fazer e influenciando diretamente nos currículos educacionais. Além disso, favorecia o aumento da diferença social entre as classes econômicas, pois as instituições escolares públicas referendavam competências direcionadas para a prática, para permitir um trabalho/emprego "futuro" para seus alunos e alunas. Já o ensino para as elites, rotineiramente no ambiente privado de ensino, acabava por primar pelo ensino da cientificidade, do conhecimento que vai além do saber-fazer (SAVIANI, 2012). Nesse sentido, podemos sugerir que seria então um aprendizado que dominaria o saber-fazer, acabando por fortalecer as de- 
A adequação à exploração do mercado de trabalho via segmentação da Licenciatura...

Carla Chagas Ramalho • Fernanda de Souza Cardoso

sigualdades, compreendendo que o conhecimento científico não é necessário para todos(as), mas apenas para uma elite dominante.

Este cenário de reformulação das Diretrizes Curriculares, voltada para as demandas do neoliberalismo, não seria diferente para a graduação em Educação Física, como veremos no próximo tópico.

DCNEF - Resolução no 03/1987 e Resolução no 07/2004

Para começarmos a entender as resoluções no 03/1987 e no 07/2004, dentro da complexidade que Ihes cabem, primeiramente precisamos entender que elas trouxeram a separação do curso em duas áreas, cada um com seu propósito. A Resolução no 03/1987 trouxe a terminologia Bacharelado, como podemos ver:

$\S 2^{\circ}$ Cada Instituição de Ensino Superior (IES), partindo dessas quatro áreas [conhecimento filosófico, conhecimento do ser humano, conhecimento da sociedade, conhecimento técnico], elenco de disciplinas da parte de Formação Geral do currículo pleno, considerando as peculiaridades de cada região e os perfis profissionais desejados (Bacharelado e/ou Licenciatura Plena) (BRASIL, 1987, grifo nosso).

Embora o texto acima referenciado apresente o termo Bacharelado, não é proposto, ainda, a fragmentação do curso de forma prática. Já a Resolução no 07/2004 estabeleceu esse novo momento do curso. É crucial a compreensão que a Resolução no 07/2004 foi a primeira após a regulamentação da profissão em Educação Física. Este fato é bastante relevante para todo o processo, pois mostra uma mudança de paradigma para a área de Educação Física, que se escorava na movimentação econômica que norteava o Brasil na década de 1990, voltada para o neoliberalismo, como já visto acima. 
A adequação à exploração do mercado de trabalho via segmentação da Licenciatura... Carla Chagas Ramalho • Fernanda de Souza Cardoso

Cabe ressaltar que uma das fundamentações para pleitear a necessidade da regulamentação da profissão foi justamente a atuação em áreas distintas aos ambientes ditos escolares. As academias de ginásticas e de musculação, por exemplo, estavam cada vez mais ganhando espaço e amplitude na prática social e se tornando um negócio frutífero dentro da contextualização capitalista. Poderia, então, se tornar mais um setor com intensa presença de profissionais da área de Educação Física e com grande potencial mercadológico.

\begin{abstract}
A partir do momento em que as academias de ginástica passam a ser administradas como um negócio que envolve capital elevado e necessita de retorno economicamente viável, o movimento é um só: o de incorporação de técnicas e teorias administrativas que vão configurar a gestão e a organização do trabalho neste espaço de forma racionalizada (FURTADO, 2009, p. 5).
\end{abstract}

Com um terreno fértil para a exploração capitalista (buscando a mais valia para gerar mais lucro), como também a possibilidade política desse período que buscava reduzir mais a atuação do Estado, em prol do Estado Mínimo (ideais neoliberais), a regulamentação da profissão se deu no dia 1 de setembro de 1998 pela lei 9.696, no então governo do presidente Fernando Henrique Cardoso, ratificando todo o cenário já descrito por nós. Nesta mesma lei foi designada a criação do Conselho Federal de Educação Física (CONFEF) e os Conselhos Regionais de Educação Física (CREF), tendo como função registrar todos(as) os(as) formados(as) na área para possibilitar a atuação dos(as) mesmos(as) (BRASIL, 1998). Ou seja, a lei mostra uma relação intrínseca da atuação do(a) formando(a) em Educação Física com os conselhos criados à época e o Estado como responsável por ceder poderes na instância pública para uma instituição privada, como é o sistema CONFE/CREFs:

O sistema CONFEF/CREFs tornou-se o primeiro Conselho profissionalizante que surgiu como uma entidade privada, garantida 
A adequação à exploração do mercado de trabalho via segmentação da Licenciatura... Carla Chagas Ramalho • Fernanda de Souza Cardoso

graças à Medida Provisória n 36 (MP 36) que, via políticas neoliberais, buscava o Estado mínimo para a classe dominada e o Estado máximo para a classe dominante. A MP 36 possibilitava que os Conselhos não fossem mais administrados pelo setor público (DE PAULA et al., 2018, p. 283).

Assim, surgiu a Resolução $n^{\circ}$ 07/2004, embasada por ideais capitalista/neoliberais e já fundamentada pelo Parecer n 0058/2004. Este parecer mostra a atuação do sistema CONFEF/CREF para a separação na área de atuação do curso em Licenciatura e Bacharelado e aponta para reuniões e debates acerca da temática no território nacional, guiados por conselheiros do referido sistema. Buscando pôr em xeque a Educação Física de formação ampliada em busca de uma estruturação em campos de conhecimento, foi proposto “[...] um novo tipo de formação - o Bacharelado - para além da licenciatura plena" (BRASIL, 2004a).

Então, temos o fomento do ideário das competências (PERRENOUD, 2000) na formação de graduação para todos os cursos e, na área da Educação Física, nós também temos um campo de exploração novo, o Bacharelado. Dessa forma, a Resolução $n^{\circ}$ 07/2004 busca se apropriar dessas demandas de forma institucionalizada, gerando áreas de atuação segmentadas, mas respeitando as normatizações definidas para as graduações, utilizando assim um jogo de palavras para não romper os limites da legalidade. Acreditamos que por esse motivo o termo "Bacharelado" não surge em nenhum momento nesse documento, pois a especificidade do momento era em detrimento do currículo de Licenciatura, no qual fica exigido "[...] a definição de currículos próprios da Licenciatura que não se confundam com o Bacharelado ou com a antiga formação de professores que ficou caracterizada como modelo '3+1'" (BRASIL, 2001).

Assim, na Resolução n 007/2004 temos os termos "graduados em Educação Física" e "licenciatura plena em Educação Física", definindo a qualificação necessária para cada área: 
A adequação à exploração do mercado de trabalho via segmentação da Licenciatura... Carla Chagas Ramalho • Fernanda de Souza Cardoso

Art. $4^{\circ} \mathrm{O}$ curso de graduação em Educação Física deverá assegurar uma formação generalista, humanista e crítica, qualificadora da intervenção acadêmico-profissional, fundamentada no rigor científico, na reflexão filosófica e na conduta ética.

$\S 1^{\circ} \mathrm{O}$ graduado em Educação Física deverá estar qualificado para analisar criticamente a realidade social, para nela intervir acadêmica e profissionalmente por meio das diferentes manifestações e expressões do movimento humano, visando a formação, a ampliação e o enriquecimento cultural das pessoas, para aumentar as possibilidades de adoção de um estilo devida fisicamente ativo e saudável.

$\S 2^{\circ}$ O Professor da Educação Básica, licenciatura plena em Educação Física, deverá estar qualificado para a docência deste componente curricular na educação básica, tendo como referência a legislação própria do Conselho Nacional de Educação, bem como as orientações específicas para esta formação tratadas nesta Resolução (BRASIL, 2004b, grifo nosso).

Curioso observar que, mesmo a Resolução n 03/1987 já tendo trazido o termo Bacharelado para a arena, a modificação do cenário dos anos 2000 se ateve a referenciar a segmentação de forma um tanto quanto mais velada, por conta das alterações curriculares que o contexto trazia e das novas legislações já promulgadas. Como De Paula et al. (2018, p. 286) sinalizam, a Lei de Diretrizes e Bases (LDB) e o Parecer n 400/2005 já apontavam "[...] que toda graduação é plena e que toda licenciatura é compreendida como uma graduação".

Assim, de fato temos um terreno fértil para a criação curricular de cursos específicos de Licenciatura e Bacharelado, e mesmo com as novas Diretrizes Curriculares em Educação Física não sendo incisivas, as instituições de ensino superior se aproximavam mais do setor privado e das diretrizes ditadas pelo mercado através de parcerias entre a sociedade civil, permitindo a elas firmarem contratos ou ainda realizar cursos pagos (SHIROMA; MORAES; EVANGELISTA, 2011). Acreditamos que tudo isso auxiliou para que 
A adequação à exploração do mercado de trabalho via segmentação da Licenciatura... Carla Chagas Ramalho • Fernanda de Souza Cardoso

a graduação em Educação Física se conciliasse com o mundo fitness, clubes esportivos, entre outros setores fora do contexto da Educação Básica que estavam cada vez mais cheios de possibilidades novas para o sistema capitalista (e aos que o alimentam), um mercado novo, reluzindo como ouro.

Após esse momento de embates vindos das décadas de 1990 e dos anos 2000, fundaram-se, então, os cursos em Licenciatura em Educação Física e Bacharelado em Educação Física, em muito legitimados por estudiosos(as) do campo na época, como nos alerta Furtado (2020). A seguir, vamos ver como essa segmentação curricular refletiu no mercado de trabalho e na realidade social vigente, mostrando que não há como falar de trabalho, na atual conjuntura, sem falar da exploração capitalista que norteia toda a formação profissional.

\section{Bacharelado x Licenciatura - mercado de trabalho e realidade social}

Para conseguirmos explanar a complexidade da necessidade mercadológica capitalista da divisão do curso de Educação Física, faremos uma síntese das necessidades do mercado que resultaram na conformidade de estudiosos(as) da área em relação à fragmentação do curso (FURTADO, 2020).

Precisamos ter clareza que, para o capitalismo se fortalecer, necessita ter mercado. Se precisa de mercado, precisa de trabaIhadores(as) por um lado (mão de obra produtiva), e da classe dominante por outro (que disponibilize capital e condições para conceder matéria prima, seja ela qual for, em qual área for), para possibilitar a produção de mercadorias. Assim, a classe dominante somente gera mais capital para si, concedendo uma pequena quantia resultante do produto gerado, ou seja, a mais valia. ${ }^{1} \mathrm{O} / \mathrm{A}$

\footnotetext{
1 Para compreender a teoria da mais-valia é necessário que se tenha em conta que o valor criado no processo produtivo é superior ao valor da força de trabalho, dividindo-se em duas partes: a) Uma que corresponde ao valor da força de trabalho, como mercadoria, que se traduz, em termos concretos, no salário, e que constitui o custo de produção da força de trabalho na ótica do capitalista (e que configura rendimento para o trabalhador e/ou trabalhadora); b) Outra parte do valor criado no processo produtivo que excede o valor da força de trabalho e que é propriedade do capitalista. Ao excedente do valor gerado pelo trabaIhador sobre o valor recebido, Marx nominou de processo de "mais-valia" (DONÁRIO; SANTOS, 2016).
} 
A adequação à exploração do mercado de trabalho via segmentação da Licenciatura... Carla Chagas Ramalho • Fernanda de Souza Cardoso

trabalhador(a) vende sua mão de obra, sua força de trabalho e conhecimento, gera um produto de valor bem superior ao que ele recebe por ter criado tal mercadoria (MARX, 2013). Os exemplos apresentados nos estudos de Marx e Engels (1999) refletem o cenário industrial, mas devemos trazer essa realidade para distintas possibilidades de trabalho e, no caso desta pesquisa, para as questões atuais da década de 1990 e dos anos 2000. Neste período, o meio de produção capitalista se reinventava através do toyotismo, ${ }^{2}$ buscando evitar desperdício, transformar a produção menos especializada e tendo como principal foco o aumento do lucro para a classe dominante (BORGES et al., 2011).

Entramos nos anos 2000 com a tendência à cooptação da classe trabalhadora e destruição dos seus organismos de luta para que os ajustes estruturais, os planos de austeridade, fossem aplicados e aprofundados. Entramos nos anos 2000, mais uma vez, com o capital em franca agonia arrastando a classe trabalhadora à destruição. Isto é evidente nos ajustes estruturais e na austeridade cada vez mais aprofundada para manter a hegemonia do sistema. Países vão à bancarrota e levam consigo direitos e conquistas da classe (TAFFAREL, 2012, p. 4).

Nesse cenário, encaixamos a realidade que refletiu na real divisão curricular do curso em Educação Física que possibilitou meIhor exploração desse mercado de trabalho pela elite, detentora do capital. Acreditamos que a divisão em dois campos de atuação da Educação Física (Licenciatura e Bacharelado) condiz com o propósito capitalista que almeja ampliar o seu mercado (possuindo duas áreas distintas e demarcadas para a atuação profissional), dispondo de mais possibilidades de produtos/mercadorias/serviços que podem ser explorados, como também aumenta o número de trabalhadores(as) para a área, promovendo assim uma desvalorização do proletariado e um maior acúmulo de capital para a

2 "O modelo toyotista tentava potencializar o rendimento do trabalho através da união de todos em equipe estabelecendo a competição. No toyotismo articulavam habilidades cognitivas e comportamentais obtendo assim a automação flexível" (BORGES et al., 2011, p. 53). 
A adequação à exploração do mercado de trabalho via segmentação da Licenciatura... Carla Chagas Ramalho • Fernanda de Souza Cardoso

classe dominante. Essa leitura feita por nós traz para o contexto da Educação Física a exploração desenhada por Marx e Engels (1999).

Apontamos ainda para a não especialização restritiva, trazida pelo toyotismo, que refletiu na área educacional como o campo de competências direcionado para cada área de atuação do(a) trabaIhador(a), onde define-se o saber-fazer (dentro da sua área) como ápice da produção sem desperdício, funcionando em fluxo contínuo e de forma individual. "A polivalência, aqui entendida como profissional multifunção, passa a ser valorizada em detrimento da especialização, o trabalho em equipe e por tarefas substitui o trabalho de ritmo contínuo e realizado individualmente." (BORGES et al., 2011, p. 51).

Importante apontar que, apesar desse(a) trabalhador(a) precisar ter multifunção, a necessidade de marcar territórios de atuação é importante para delimitar as necessidades que seriam geradas para cada grupo e, acreditamos, para evitar uma coligação entre trabalhadores. Pois, segundo Marx (1999, p. 27), o trabalho assalariado "baseia-se exclusivamente na concorrência dos operários entre si", e, para a Educação Física, essa concorrência ficou demarcada pela área de habilitação designada pelo currículo formador, tendo o sistema CONFE/CREF como um xerife do mercado que controla as margens e até o centro do processo.

Após a formação das primeiras turmas sob égide da Resolução 07/2004, os CREFs, alegando respaldo na Resolução 94/2005 do CONFEF, iniciaram o processo de fiscalização que impede a atuação profissional de Licenciados em espaços distintos da educação básica, gerando reações organizadas por parte dos egressos em alguns Estados brasileiros [...] (FURTADO, 2020, p. 122).

Importante deixar claro a influência do sistema CONFEF/CREF nesse cenário de regulamentação da profissão e de segmentação das áreas de atuação do graduado em Educação Física. Para o atual e único presidente do CONFEF, durante todo o período de criação deste conselho, "era somente necessário regulamentar e 
A adequação à exploração do mercado de trabalho via segmentação da Licenciatura... Carla Chagas Ramalho • Fernanda de Souza Cardoso

a reserva de mercado estaria feita" (DE PAULA et al., 2018, p. 283). Porém, dentro do sistema capitalista, quanto maior for a quantidade da mão de obra e a desqualificação da formação acadêmica, maior será o esvaziamento teórico desses(as) futuros(as) trabaIhadores(as). Para Taffarel (2012), este processo gera duas lacunas balizares: na formação (pela negação de conhecimentos) e na atuação profissional (pela limitação nas áreas de atuação de trabalho), tendo-se em voga a pedagogia das competências, na qual:

[...] os conhecimentos orientadores da formação são de razão meramente instrumental. Toda essa relação acaba gerando para o trabalhador uma constante adaptabilidade nas suas competências, para manter-se na empregabilidade nos campos de trabalho. Isso significa que, periodicamente, o trabalhador despende tempo para se atualizar às novas necessidades geradas pelo mercado (IORA; SOUZA; PRIETTO, 2017, p. 471).

Assim, com a fragmentação do curso, devido à demanda do sistema econômico vigente, a Educação Física acabou por se fragilizar e tornar-se um conhecimento incompleto, privando esses(as) trabalhadores(as) de pensar nas necessidades sociais de forma ampla (IORA; SOUZA; PRIETTO, 2017). Compreendendo que essa demanda atropela a formação de forma direta, zelamos por uma formação inicial na área ampla, onde a especialização para o mercado de trabalho seja feita de forma posterior à graduação, sem ferir os conhecimentos científicos básicos que são inerentes à atuação docente do graduado em Educação Física. Pois, reforçamos nesta pesquisa, a área de atuação do(a) formado(a) em Educação Física depende estruturalmente da ação da prática docente e a sua função é inerentemente pedagógica em diferentes áreas de atuação.

E por ter a dimensão da complexidade necessária para a formação docente (a interseção entre os conhecimentos pedagógicos com os conhecimentos científicos atribuídos), entendemos que a formação inicial deve ser ampla e generalista, e que deve haver possibilidades para formação continuada com especialização 
A adequação à exploração do mercado de trabalho via segmentação da Licenciatura...

Carla Chagas Ramalho • Fernanda de Souza Cardoso

voltada para área de atuação profissional escolhida por cada trabalhador(a). De acordo com pesquisa realizada por lora, Souza e Prietto (2017), há um retorno do egresso em Educação Física para complementação do curso de forma recorrente, almejando uma formação ampliada, por sentirem tal necessidade quando ingressam no mercado de trabalho.

Neste tópico ficou explanado como o sistema capitalista e seu mercado de trabalho agiram e agem com sua mão invisível (ou às vezes bem visível) no processo de formação da graduação em Educação Física, gerando uma precarização na formação profissional. Acreditamos que, com o passar dos anos, ficará cada vez mais latente uma inconsistência desse trabalho e desse(a) trabalhador(a).

\section{Considerações Finais}

Neste trabalho, apresentamos a relação direta e implícita da construção curricular de Educação Física com o mercado de trabaIho e com a formação de futuros(as) trabalhadores(as). Mostramos como a segmentação do curso acabou por permitir uma oxigenação no sistema capitalista, porém à custa da precarização do conhecimento e da área de atuação para esses(as) trabalhadores(as).

Assim, ratificamos que a essência da formação inicial do curso de Educação Física não deve sofrer gerência direta do mercado de trabalho ou de sistemas que ainda visam regularizar a profissão no setor mercadológico. Acreditamos que a Educação Física deve voltar-se para seus conhecimentos primários em busca de um diálogo com a realidade social que a embasa, sem limitar ou ser limitante no processo de ensino aprendizagem.

Enfim, esperamos que com estas problematizações, que não são inéditas, mas que ganham reforço com o passar dos anos e com cada vez mais trabalhadores(as) formados(as) nessa perspectiva fragmentada da Educação Física, possamos reforçar o diálogo a favor de uma Educação Física que tenha todos os seus conhecimen- 
A adequação à exploração do mercado de trabalho via segmentação da Licenciatura...

Carla Chagas Ramalho • Fernanda de Souza Cardoso

tos enaltecidos em prol da sociedade. Ao contrário de fragmentar os conhecimentos e saberes incorporados pela área, procuremos relacioná-los, demonstrando o quanto eles estão interligados para não corrermos o risco de fragmentarmos ainda mais os pensamentos, as práticas e a própria sociedade. Apreciamos a busca constante e crítica para a prática corporal ser trabalhada dentro da sua complexidade social, buscando participar para auxiliar a formação e conscientização de cidadãos e cidadãs críticos(as).

\title{
Referências
}

\begin{abstract}
ALTHUSSER, Louis. Ideologia e aparelhos ideológicos de Estado. Lisboa: Editorial Presença, 1980.

BORGES, Alex Rodrigo et al. Toyotismo: uma análise do trabalho e da educação na produção capitalista. Revista Brasileira de
\end{abstract} Educação e Cultura, Minas Gerais, n. iv, jul.-dez., 2011, p. 45-59. Disponível em: https://periodicos.cesg.edu.br/index.php/educacaoecultura/article/view/51. Acesso em: 23 ago. 2020.

BRASIL. Conselho Federal de Educação. Parecer n. 215, de 11 de março de 1987. Documento n. 315, Brasília, março, 1987. Disponível em: http://crefrs.org.br/legislacao/pdf/resol_ cfe_3_1987.pdf. Acesso em: 20 ago. 2019.

BRASIL. Lei $\mathbf{n}^{\circ} \mathbf{9 . 6 9 6}$ de $\mathbf{1}^{\circ}$ se setembro de 1998 . Dispõe sobre a regulamentação da profissão de Educação Física e cria os respectivos Conselho Federal e Conselhos Regionais de Educação Física. Disponível em: http://www.planalto.gov.br/ccivil_03/leis/l9696. htm. Acesso em: 19 ago. 2020.

BRASIL. Ministério da Educação. Conselho Nacional de Educação. Parecer no 009/2001. Diretrizes para a Formação de Professores da Educação Básica, em nível superior, curso de licenciatura, de graduação plena. Disponível em http://portal.mec.gov.br/cne/ arquivos/pdf/009.pdf. Acesso em: 20 ago. 2020. 
A adequação à exploração do mercado de trabalho via segmentação da Licenciatura... Carla Chagas Ramalho • Fernanda de Souza Cardoso

BRASIL. Ministério da Educação. Conselho Nacional de Educação. Parecer no 0058/2004. Diretrizes Curriculares Nacionais para os cursos de graduação em Educação Física. Brasília: Ministério da Educação, 2004a. Disponível em: http://portal.mec.gov.br/cne/ arquivos/pdf/2007/pces058_04.pdf. Acesso em: 20 ago. 2020.

BRASIL. Ministério da Educação. Conselho Nacional de Educação/ Câmara de Educação Superior. Resolução $n^{\circ}$ 7, de 31 de março 2004. Institui as diretrizes curriculares nacionais para os cursos de Educação Física, em nível superior de graduação plena. Brasília: Ministério da Educação, 2004b. Disponível em: http:// portal.mec.gov.br/cne/arquivos/pdf/ces0704edfisica.pdf. Acesso em: 20 de ago. 2020.

DE PAULA, Alisson Slider do Nascimento et al. Formação em Educação Física e a regulamentação da profissão: sistema CONFEF/CREFS e a divisão curricular. Debates em Educação, Maceió, v. 10, n. 21, p. 279-292, ago. 2018. ISSN 2175-6600. Disponível em: https://www.seer.ufal.br/index.php/debateseducacao/article/view/4272. Acesso em: 20 ago. 2020.

DONÁRIO, Arlindo Alegre; SANTOS, Ricardo Borges. Da Bíblia à neuroeconomia: o porquê do estado do pensamento económico actual. Lisboa: Edições Sílabo; Lisboa: Universidade Autónoma de Lisboa, 2016.

\section{FORGRAD. Plano Nacional de Graduação: um projeto em}

construção. Maio de 2000. Disponível em: http://portal.mec.gov. br/sesu/arquivos/pdf/DocDiretoria.pdf. Acesso em: 22 set. 2020.

FURTADO, Roberto Pereira. Do fitness ao Wellnes: os três estágios de desenvolvimento das academias de ginásticas. Pensar a Prática. Goiânia, v. 12, n. 1, p. 1-11, jan-abr 2009. Disponível em: https://www.revistas.ufg.br/fef/article/download/4862/5345. Acesso em: 22 set. 2020.

FURTADO, Roberto Pereira. Novas diretrizes e antigos debates: uma análise das Diretrizes Curriculares para a Graduação em Educação Física - Resolução CNE/CES 06/2018. In: SOARES, Marta Genú; ATHAYDE, Pedro; LARA, Larissa (orgs.). Formação pro- 
A adequação à exploração do mercado de trabalho via segmentação da Licenciatura...

fissional e o mundo de trabalho. Natal, RN: EDUFRN, 2020. p. 115-136.

IORA, Jacob Alfredo; SOUZA, Maristela da Silva; PRIETTO, Adelina Lorensi. A divisão licenciatura/bacharelado no curso de Educação Física: O olhar dos egressos. Movimento, Porto Alegre, v. 23, n. 2, p.461-474, 2017. Disponível em: https://seer.ufrgs.br/Movimento/ article/view/63979. Acesso em: 22 set. 2020.

MARCONI, Marina de Andrade; LAKATOS, Eva Maria. Metodologia do trabalho científico: procedimentos básicos, pesquisa bibliográfica, projeto e relatório, publicações e trabalhos científicos. 6 ed. São Paulo: Atlas, 2003.

MARX, Karl; ENGELS, Friedrich. O manifesto comunista (1848). Versão para eBook: eBooksBrasil.com. Fonte Digital: RocketEdition, 1999.

MARX, Karl. O Capital: crítica da Economia Política. Livro 1. São Paulo: Boitempo, 2013.

MOREIRA, Eduardo. Desigualdade \& caminhos para uma sociedade mais justa. Rio de Janeiro: Civilização Brasileira, 2019.

MOREIRA, Eduardo. Economia do desejo: a farsa da tese neoliberal. Rio de Janeiro: Civilização Brasileira, 2020.

NASCIMENTO, Francielle Pereira; BARROS, Marta Silene Ferreira. O sistema capitalista a partir da década de 1990 e suas implicações na educação escolar brasileira. Revista Ibero-Americana de Estudos em Educação, Araraquara, v. 13, n. 4, p. 1779-1791, out. 2018. Disponível em: https://periodicos.fclar.unesp.br/iberoamericana/article/view/9815. Acesso em: 22 set. 2020.

PERRENOUD, Philippe. Dez novas competências para ensinar. Porto Alegre: Artmes, 2000.

RAMOS, Marise Nogueira. A pedagogia das competências: autonomia ou adaptação? 3 ed., São Paulo. Cortez. 2006.

SAVIANI, Dermeval. Pedagogia histórico-crítica: primeiras aproximações. Campinas, SP: Autores Associados, 2011. 
A adequação à exploração do mercado de trabalho via segmentação da Licenciatura... Carla Chagas Ramalho • Fernanda de Souza Cardoso

SAVIANI, Dermeval. Escola e democracia. Campinas: Autores associados, 2012.

SHIROMA, Eneida Oto; MORAES, Maria Célia Marcondes de; EVANGELISTA, Olinda. Política Educacional. Rio de janeiro: Lamparina, 2011.

SILVA, Mônica Ribeiro da; ABREU, Cláudia Barcelos de Moura. Reformas para quê? As políticas educacionais nos anos de 1990, o "novo projeto de formação" e os resultados das avaliações nacionais. Perspectiva, Florianópolis, v. 26, n. 2, p. 523-550, jan. 2008. ISSN 2175-795X. Disponível em: https://periodicos.ufsc.br/index. php/perspectiva/article/view/2175-795x.2008v26n2p523. Acesso em: 22 set. 2020.

TAFFAREL, Celi Zulke. A formação de professores de educação física e a licenciatura ampliada. In: SEMANA DE EDUCAÇÃO FÍSICA/UFMS, 17, 2012, Campo Grande (MS); JORNADA DE INICIAÇÃO CIENTÍFICA DO CURSO DE EDUCAÇÃO FÍSICA /UFMS, 4., 2012, Campo Grande (MS). Anais [...]. Campo Grande: UFMS, 2012. Disponível em: https://repositorio.ufba.br/ri/bitstream/ ri/18055/1/TAFFAREL\%202012\%20-\%20EVENTO\%20UFMS.pdf. Acesso em: 28 ago. 2020.

YOUNG, Michael, F. D. Teoria do currículo: o que é e por que é importante. Cadernos de Pesquisa, São Paulo, v. 44, n. 151, p. 190-202, mar. 2014.

\section{Publisher}

Universidade Federal de Goiás. Faculdade de Educação Física e Dança. Publicação no Portal de Periódicos UFG. As ideias expressadas neste artigo são de responsabilidade de seus autores, não representando, necessariamente, a opinião dos editores ou da universidade. 